\title{
Pengentasan Kemiskinan Melalui Social Preneur Bagi Ibu-Ibu PKK
}

\author{
Budi Ilham Maliki ${ }^{1}$,Achmad Nashrudin ${ }^{2}$ \\ ${ }^{1}$ budi.ilham@binabangsa.ac.id; ${ }^{2 n a s h r u d i n . a c h m a d @ g m a i l . c o m ~}$ \\ ${ }^{1}$ Program Studi, Magister Manajemen, Universitas Bina Bangsa; \\ ${ }^{2}$ Prodi manajemen FEB Universitas Bina Bangsa
}

\begin{abstract}
This activity is intended to assist in poverty alleviation efforts through empowerment and gender approaches, namely empowering PKK mothers by fostering social principles in PKK organizations and activities. This activity will provide skills training according to partners' interests, so that partners are able to produce superior products that have economic value and are needed by the market. These products are not only for marketing but also for own consumption, and reduce the burden on partners' spending in financing household consumption. To develop social preneur, which aims at social (poverty alleviation), training on entrepreneurial motivation and entrepreneurial managerial skills is also given, covering production management, financial management, simple accounting and marketing management. The results of these activities are: 1) Reducing the burden of consumption costs for household goods for the families of partner PKK mothers, (2) Establishing social principles for PKK RW partner women who are able to provide additional income to PKK member families, and 3) Creating products household goods and convection produced by partner PKK that are marketable
\end{abstract}

Keywords: poverty alleviation, social preneuer, empowerment, gender

\begin{abstract}
Abstrak
Kegiatan ini hendak membantu dalam upaya pengentasan kemiskinan melalui pendekatan pemberdayaan dan gender, yakni pemberdayaan ibu-ibu PKK dengan menumbuh kembangkan social preneur pada organisasi dan kegiatan PKK. Kegiatan ini akan memberikan pelatihan ketrampilan sesuai peminatan mitra, agar mitra mampu menghasilkan produk unggulan yang memiliki nilai ekonomis dan dibutuhkan pasar. Produk tersebut selain untuk dipasarkan juga untuk dikonsumsi sendiri, dan mengurangi beban pengeluaran mitra dalam membiayai konsumsi rumah tangga. Untuk menumbuhkembangkan social preneur, yang bertujuan sosial (pengentasan kemiskinan), diberikan pula pelatihan motivasi kewirausahaan dan ketrampilan manajerial kewirausahaan, yang mencakup manajemen produksi, manajemen keuangan, akuntansi sederhana dan manajemen pemasaran. Luara kegiatan ini adalah: 1) Pengurangan beban biaya konsumsi barang kebutuhan rumah tangga pada keluarga ibu-ibu PKK mitra,(2) Terbentuknya social preneur Ibu-lbu PKK RW mitra yang mampu memberikan penghasilan tambahan kepada keluarga anggota PKK, dan 3) Terciptanya produk barang kebutuhan rumah tangga dan konveksi hasil produksi PKK mitra yang layak dipasarkan.
\end{abstract}

Kata kunci: pengentasan kemiskinan, social preneuer, pemberdayaan, gender

\section{PENDAHULUAN}

Masalah kemiskinan merupakan salah satu fenomena sosial yang masih harus diselesaikan oleh bangsa dan negara ini dan semakin hari masalahnya juga semakin kompleks. Kemiskinan merupakan fenomena sosial yang sifatnya multi-dimensi, tidak hanya terkaitkan dengan masalah ekonomi saja, tetapi juga berkaitan dengan masalah-

\footnotetext{
${ }^{1}$ Dosen Tetap Pasca Sarjana Prodi Magister Manajemen Universitas Bina Bangsa

2 Dosen Tetap Prodi Manajemen FB Unversitas Bina Bangsa
} 
masalah sosial, budaya dan politik (Moeljarto, 1994). Dalam upaya pemahaman dan identifikasi kemiskinan pada umumnya, pemahaman pada pengertian subsistensi dengan dimensi ekonomi lebih mengedepan dan lebih banyak dipakai, dimana kemiskinan diartikan sebagai keterbatasan sumber-sumber ekonomi untuk mempertahankan kelangsungan hidup yang layak. Fenomena kemiskinan ekonomi umumnya dikaitkan dengan kekurangan pendapatan untuk memenuhi kehidupan layak tersebut (Esmara, 1986), dan apa yang terjadi pada kemiskinan bergantung pada apa yang terjadi pada distribusi pendapatan dan konsumsi (Deaton, 2003).

Kemiskinan di Provinsi Banten pada tahun 2020 masih cukup tinggi. Berdasar data Badan Pusat Statistik (BPS) bahwa per September 2020 jumlah penduduk miskin di Banten sebanyak 704.750 ribu jiwa (5,92\%) dari jumlah penduduk Propinsi Banten keseluruhan sebanyak 11.904.562 juta jiwa (lihat Tabel 1.1.)

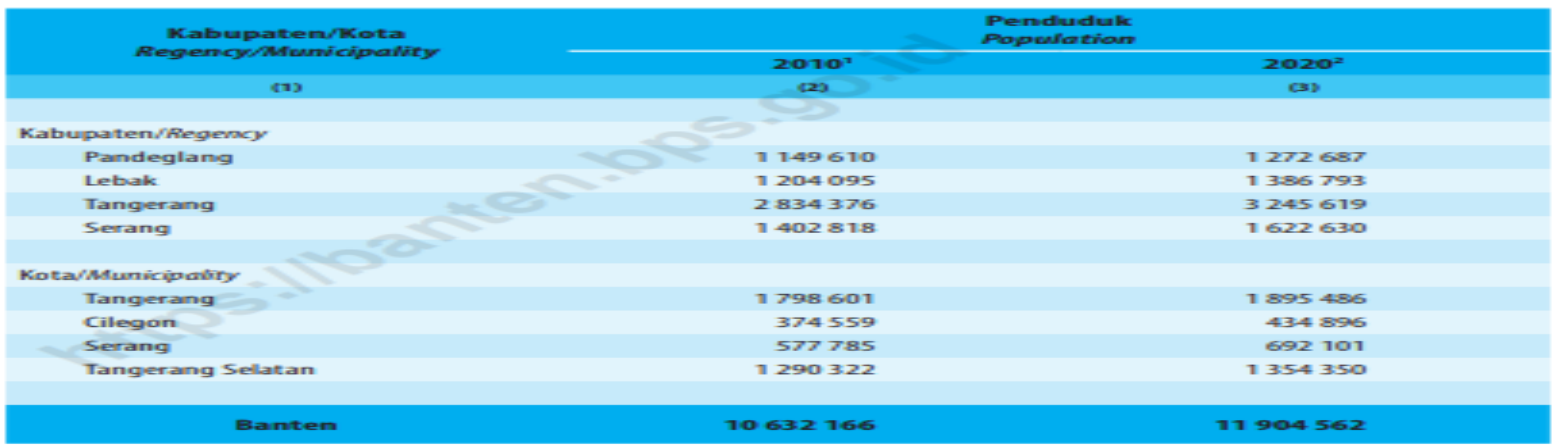

Tabel 1.2.

Jumlah Penduduk Miskin di Provinsi Banten tahun 2019 dan 2020

\begin{tabular}{|c|c|c|c|c|}
\hline \multirow{2}{*}{$\begin{array}{l}\text { Kabupaten/Kota } \\
\text { Regemcy/Mennicipality }\end{array}$} & \multicolumn{2}{|c|}{$\begin{array}{l}\text { Jumlah Penduduk Miskin } \\
\text { (ribu)/Mumber of Paor People } \\
\text { (thousand) }\end{array}$} & \multicolumn{2}{|c|}{$\begin{array}{l}\text { Persentase Penduduk Miskin } \\
\text { Pencentage of Poour People }\end{array}$} \\
\hline & 2019 & 2020 & 2019 & 2020 \\
\hline (a) & (2) & (3) & $\Leftrightarrow$ & (5) \\
\hline \multicolumn{5}{|l|}{ Kabupaten/Regency } \\
\hline Pandeglang & 114.09 & 120,44 & 9,42 & 9,92 \\
\hline Lebak & 107.93 & 120.83 & 8,30 & 9,24 \\
\hline Tangerang & 193,97 & 242,02 & 5,14 & 6,23 \\
\hline Serang & 61.54 & 74.80 & 4,08 & 4,94 \\
\hline \multicolumn{5}{|l|}{ Kata/Meuniciaganity } \\
\hline Tangerang & 98,37 & 118,22 & 4,43 & 5,22 \\
\hline Cilegan & 13,20 & 16,31 & 3,03 & 3,69 \\
\hline Serang & 36,21 & 42,24 & 5,28 & 6,06 \\
\hline Tangerang Selatan & 29,16 & 40,99 & 1,68 & 2,29 \\
\hline Banten & 654.46 & 775,99 & 5.09 & 5.92 \\
\hline
\end{tabular}

Berdasarkan https://www.rmolbanten.com/read/2019/11/04/12724, yang berisi rilis Kementrian Pembangunan dan Desa Tertinggal dan Transmigrasi, yang menyebutkan bahwa Kabupaten Pandeglang merupakan kabupaten yang memilik Desa tertinggal yang paling tinggi, selain Kabupten Lebak. Di Kabupten Pandelang, yang terdiri dari 326, 127 Desa tertinggal dan 4 desa sangat tertinggal, Kabuptaen Pandeglang. Sampai dengan akhir tahun 2020, dari keseluruhan penduduk Kabnupten Pandeglang yang mencapai 1.272.687 jiwa, sebanyak 126.251 jiwa (9,92\%). Berdasarkan data Kemendes, 127 desa tertinggal itu tersebar di beberapa kecamatan di Pandeglang. Sementara, empat diantaranya 
yang masuk kategori desa sangat tertinggal yaitu Desa Cikiruh di Kecamatan Cibitung, Desa Sukamula di Kecamatan Cikeusik serta Desa Sudimanik dan Curug di Kecamatan Cibaliung (sumber : https://news.detik.com. (9 Maret 2021).

Bahwa dalam upaya untuk mengentaskan kemiskinan diperlukan upaya untuk memberikan kesempatan yang sama kepada penduduk laki-laki dan perempuan dalam memenuhi kebutuhan keluarganya, dengan lebih memberdayakan kaum perempuan agar ikut serta dan diperhitungkan dalam lapangan pekerjaan yang mampu menghasilkan keuntungan (Suyono, 2008) yang pada akhirnya dapat membantu menopang pemenuhan kebutuhan hidup seluruh keluarganya. Dalam pengentasan kemiskinan melalui pemberdayaan perempuan terdapat beberapa pilar, yang diantaranya adalah pemberdayaan dalam bidang pendidikan dan pelatihan, yang memungkinkan kaum perempuan bisa berpikir rasional dan mampu menghasilkan ide-ide cemerlang yang bisa diterapkan sebagai kegiatan nyata di lapangan. Kegiatan nyata itu harus "laku jual" sehingga menghasilkan nilai tambah untuk kehidupan yang lebih sejahtera (Suyono, 2008).

Pengentasan kemiskinan melalui pemberdayaan perempuan, akan dilakukan dengan bekerja sama dan menggunakan jejaring oranisasi ibu-ibu PKK (pemberdayaan kesejahteraan keluarga). Dimana selain jejaring organisasi PKK terorganisir secara baik juga kegiatannya sudah melembaga dan menjadi bagian dari kehidupan masyarakat. Aktivitas kegiatan ibu-ibu PKK di Kabupaten Pandeglang pada umumnya lebih banyak terkonsentrasi pada tingkat Rukun Warga (RW) dan Desa. Karena pada kedua tingkat entitas tersebut kegiatan PKK menyentuh dan dirasakan langsung oleh warga masyarakat, khususnya di Desa Curug Kecamatan Cibaliung, Kabupaten Pandeglang.

\section{METODE}

Pelaksanaan kegiatan dilakukan di Gedung Desa Curug. Kegiatan ini diarahkan bagi ibu-ibu PKK, dengan tahapan sebagai berikut :

1. Melakukan kunjungan ke kepala Desa Curug, se;letelah berkoordinasi dengan Kepala Kecamatan Cibaliung.

2. Tim abdimas menganalisa kebutuhan, mengumpulkan bahan dan materi yang akan digunakan untuk bahan presentasi.

3. Pelaksanaan abdimas.

4. Pelatihan diberikan kepada ibu-ibu PKK pengurus Desa Curug dilokasi yang sudah disiapkan oleh pihak Mitra Abdimas, yaitu di rumah kepala Desa.

5. Pelaporan Kegiatan

6. Melakukan sejumlah analisa terhadap hasil kegiatan dan mengambil kesimpulan untuk dapat dilakukan perbaikan pada kegiatan abdimas selanjutnya.

\section{HASIL DAN PEMBAHASAN}

Kompleksitas masalah kemiskinan dikemukakan Hendriawan (2003), tidak hanya menyangkut rendahnya pendapatan dan tingkat konsumsi masyarakat, tetapi juga berkaitan dengan rendahnya tingkat pendidikan dan kesehatan, ketidakberdayaan berpartisipasi dalam pengambilan keputusan publik (powerlessness), ketidakmampuan meyampaikan 
aspirasi (voicelessness), serta berbagai masalah mengenai pembangunan manusia (human development). Pada kontek tersebut, terutama pada aspek pendidikan dan pembangunan manusia, yang rendah membawa pada rendahnya tingkat produktivitas. Sebagaimana digambarkan Malassis (1975) bahwa kemiskinan di negara-negara berkembang sebagai suatu siklus dari produktivitas yang rendah memberikan pendapatan yang rendah yang berdampak pada rendahnya tabungan, dan kemudian tingkat investasi juga menjadi rendah yang selanjutnya kembali berakibat pada rendahnya produktivitas.

Siklus kemiskinan tersebut sebagai suatu mata rantai yang akan tetap berlangsung secara terus-menerus selama tidak ada tindakan intervensi yang memotongnya. Swinkels dan Turk (2003) mengemukakan bahwa salah satu aspek penting dalam pengensatsan kemiskinan adalah dengan mengurangi kepincangan kapasitas dan ketrampilan dalam masyarakat. Dengan peningkatan kapasitas dan ketrampilan akan memberikan perkuatan produktivitas dan peningkatan penghasilan.

Upaya pengentasan kemiskinan, dilakukan dengan menumbuhkan keberdayaan keluarga miskin baik pada aspek ekonomi, melalui peningkatan pendapatan, maupun aspek non ekonomi. Pengentasan kemiskinan, dalam pendekatan pertumbuhan ekonomi, selain melalui aspek pendatan sangat perlu juga melalui aspek non pendapatan (Klasen, 2005). Aspek non pendapatan dianggap penting, karena akan memberikan kapasitas penduduk miskin dalam memberdayakan memperbaiki keadaan dirinya. Aspek non pendapatan ini ini seperti gender, kesempatan bersekolah, akses pada layanan kesehatan dan lainnya. Aspek non ekonomi (non pendapatan) lainnya yang mampu mendukung pemberdayaan keluarga miskin adalah modal sosial.Fujiwara dan Kawachi (2008, dalam Tobias, et. all,2013), modal sosial adalah sumber-sumber daya yang diakses oleh individu-individu dan kelompok-kelompok dalam sebuah struktur sosial, yang memudahkan kerjasama, tindakan kolektif, dan terpeliharanya norma-norma.

Munculnya social entrepreneurship (social preneur) menandai perlunya dorongan perubahan sosial dalam masyarakat untuk menghasilkan transformasi bermanfaat yang berkelanjutan. Sehingga munculnya social entrepreneurship penting sebagai jalan keluar masyarakat sendiri, dan bukan mengandalkan langkah dari pemerintah (Listyorini, 2012). Konsep social preneur dalam hal ini diartikan sebagai sebuah usaha bisnis yang dicipta untuk tujuan sosial, mengatasi atau mengurangi masalah sosial dan masalah kegagalan pasar, dan untuk mendorong nilai social sambil tetap beroperasi secara disiplin keuangan, invonasi dan taktik-taktik sektor bisnis (Alter, 2006 dalam Listyorini, 2012), dan usaha dan kegiatan bisnis tersebut dibangun bertolak dari kegiatan-kegiatan sosial.

Berpijak pada konsep di atas, dan sebagaimana permasalahan, kebutuhan mitra serta kondisi dan karakter mitra, yang hendak dilakukan adalah meningkatkan pendapatan keluarga melalui peningkatan ketrampilan dan kapasitas produksi mitra untuk menghasilkan produk-produk bernilai ekonomis, yang dibangun dari kelembagaan dan kegiatan sosialnya. Kepada para anggota PKK mitra akan diberikan pelatihan dan pendampingan :

1. Pelatihan ketrampilan pembuatan produk, yang meliputi :

a. Produk barang kebutuhan rumah tangga (sabun cuci serbuk, pembersih lantai dan sabun antiseptik ekstrak sirih). 
Pelatihan ini untuk menumbuhkan kemampuan memproduksi sendiri (kemandirian memenuhi) kebutuhan sendiri, yang diarahkan untuk dapat membantu mengurangi beban biaya konsumsi rumah tangga dan sekaligus (apabila memungkinkan) dapat dipasarkan kepada masyarakat luas.

b. Produk konveksi, diarahkan untuk menciptakan produk yang memiliki nilai jual tinggi dan sebagai produk unggulan mitra. Pelatihan konveksi ini akan mencakup: (1) Pelatihan desain produk (2) Pelatihan teknik penjahitan, dan (3) Branding kemasan produk

2. Pelatihan motivasi dan skil manajerial kewirausahaan, diarahkan untuk menumbuhkan motivasi perserta untuk berwirausaha dan kemampuan mengelola usaha, yang meliputi: a) Pelatihan motivasi, b) Pengenalan social preneur, c) Pembuatan perencanaan usaha, d) Manajemen operasi dan produksi, e) Manajemen pemasaran, dan f) Manajemen keuangan dan akuntansi sederhana

3. Pelatihan pemanfaatan TIK untuk pemasaran, diarahkan untuk menumbuhkan pengetahuan dan pemahaman kemudahan dalam pemasaran dengan menggunkan TIK, yang mencakup: a) Pengenalan TIK, dan jejaring media sosial internet, b) Pembuatan blog, c) Pemanfaatan TIK untuk pemasaran secara on line, d)Transaksi dalam pemasaran on line.

4. Pendampingan kepada para peserta pelatihan, dalam rangka :

a. Pemahaman dan aplikasi pengetahuan dan skil manajerial

b. Analisis potensi pasar dan pembuatan perencanaan usaha dan agar aplikatif

c. Merancang/membangun dan mengelola usaha bersama dalam bentuk social preneur melalui kegiatan PKK (mulai dari perencanaan, proses produksi, pemasaran, pengaturan mekanisme dan sistem pembagian keuntungan usaha.

Metode penyelesaian masalah tersebut secara ringkas dapat digambarkan dalam bentuk flow chat sebagai berikut : 


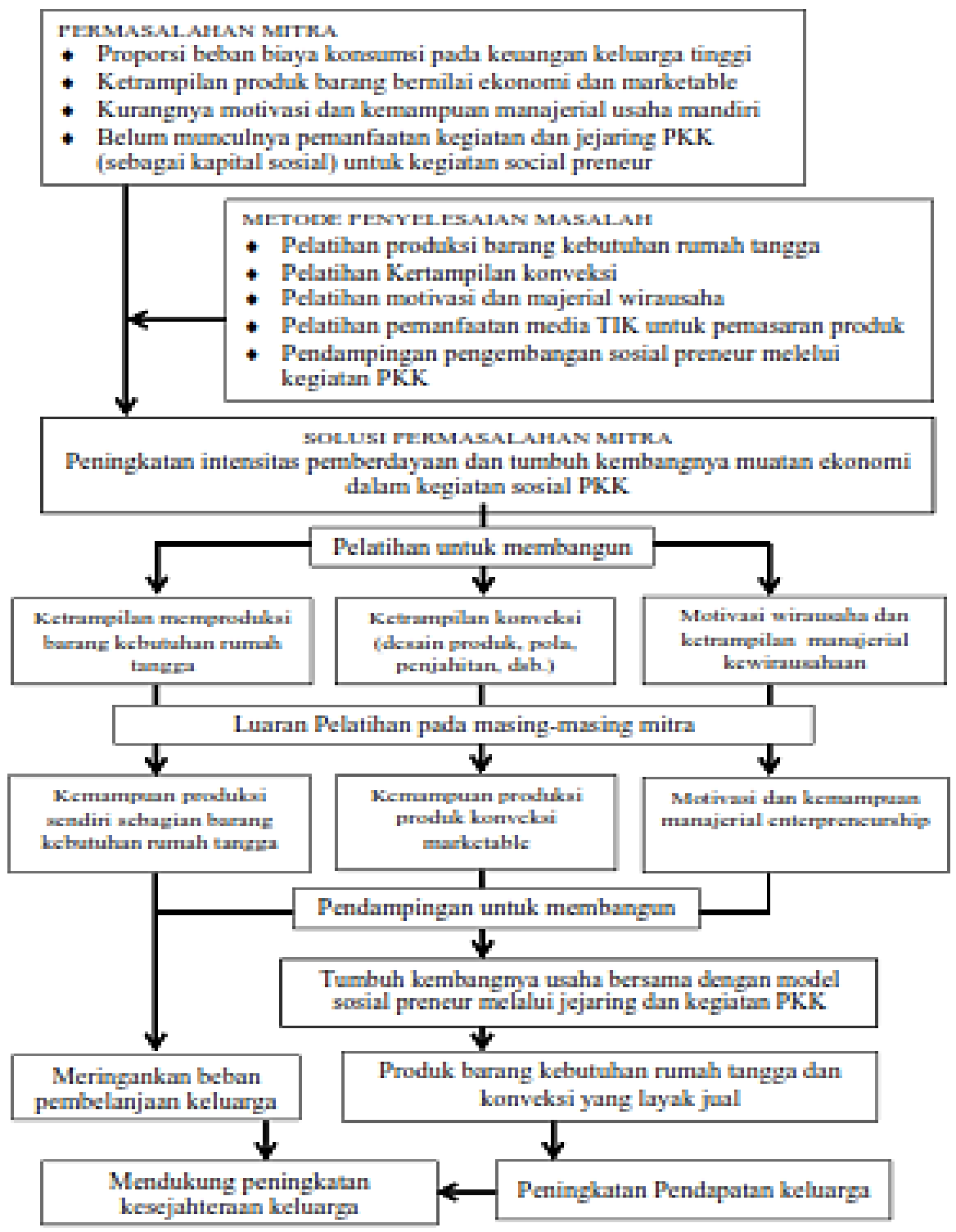

Gambar 1: Skema metode dan tahapan pelakanaan penyelesaizn masalah

\section{KESIMPULAN}

Pelaksanaan PKM ini untuk mendukung upaya pemberantasan kemiskinan pada masyarakat khususnya di Desa Curug yang terklasifikasi Daerah Tertinggal di Kabupaten Pandeglang, melalui pemberdayaan kaum perempuan (ibu-ibu PKK). Dari hasil kegiatan didap beberapa hal yang bisa disimpulkan:

1. Tumbuh-kembangnya kertampilan dan kegiatan para anggota PKK mitra yang mampu menghasilkan produk yang memiliki nilai ekonomis. 
2. Kemampuan anggota PKK di Desa Curug memproduksi sendiri sebagian barang/produk kebutuhan rumah tangga, guna mengurangi beban biaya komsumsi rumah-tangga

3. Tumbuh-kembangnya ketrampilan manajerial kewirausahaan

4. Tumbuh-kembangnya motivasi kewirausahaan dan kegiatan wirausaha diri para anggota PKK mitra, melalui kegiatan PKK.

Kegiatan Pengabdian Kepada masyarakat ini juga diharapkan memberikan output antara lain:

1. Pengurangan beban biaya konsumsi barang kebutuhan rumah tangga pada keluarga ibuibu PKK di Desa Curug.

2. Terbentuknya social preneur lbu-lbu PKK RW di Desa Curug yang mampu memberikan penghasilan tambahan kepada keluarga anggota PKK.

3. Terciptanya produk barang kebutuhan rumah tangga dan konveksi hasil produksi PKK di Desa Curug yang layak dipasarkan.

\section{UCAPAN TERIMA KASIH}

Penulis mengucapkan terima kasih kepada :

1. Bapak Camat Kecamatan Cibaliung, yang telah memfasilitasi Kepgiatan Pegambdian Pada Masyrakat ini

2. Bapak Desa Curug, Kecamatan Cibaliung yang telah memberi dukungan tempat dan pengerahan Ibu-ibu PKK;

3. Bapak Rektor Universitas Bina Bangsa Serang yang telah memberikan kepercayaan sekaligus dukungan financial terhadap pengabdian ini.

\section{DAFTAR PUSTAKA}

Badan Pusat Statistik (BPS) Banten Dalam Angka (2021).

Badan Pusat Statistik (BPS) Kabupaten Pandeglang Dalam Angka (2021).

Deaton, Angus (2003), Measuring poverty, Research Program Development Studies, Princeton University, January 2003 di internet pada http://www.wws.princenton.edu/rpds/downloads/deaton_povertymeasured.pdf

Esmara, Hendra (1986), Perencanaan dan Pembangunan Indonesia, PT, Gramedia, Jakarta.

Listyorini, Haniek (2012), Komponen dan sampak sosial enterpreneurship dalam upaya revitalisasi budaya dan insustri batik lasem Kabupaten Rembang, Dinamika Kepariwisataan Vol. XI No. 2, Oktober 2012.

Malassis, 1(1975), Agriculture and Development Process, The Unisco Press

Swinkels, Rob and Turk, Carrie (2003), Strategic Planning for Poverty Reduction in Vietnam : Progress and challenges for meeting the localized Millennium Development Goals (MDGs) (Policy Research Working Paper 2961), World Bank, January 2003 di internet path http://www.ssrn.com 
Thobias, Erwin, et all (2013), Pengaruh modal sosial terhadap perilaku kewirausanaan; Suatu studi pada pelaku usaha mikro kecil menengah di Kecamatan Kabaruan Kabupaten Kepulauan Talaud, Jurnal Acta Diurna, edisi April 2013.

Tjokrowinoto, Moeljarto, Prof Dr. MPA. (1994), Politik Pembangunan, Sebuah Analisis Konsep, Arah dan Strategi, Tiara Wacana, Yogyakarta.

https://news.detik.com. (diakses 9 Maret 2021).

https://www.rmolbanten.com/read/2019/11/04/12724 (diakses 24 Mei 2021) 